Marquette University

e-Publications@Marquette

$12-12-2017$

\title{
Unravelling the Correlation of Electronic Structure and Carrier Dynamics in CulnS2 Nanoparticles
}

\author{
Wenhui Hu \\ Marquette University \\ John Ludwig \\ Marquette University \\ Brian Pattengale \\ Marquette University \\ Sizhuo Yang \\ Marquette University \\ Cunming Liu \\ Argonne National Laboratory \\ See next page for additional authors \\ Follow this and additional works at: https://epublications.marquette.edu/chem_fac \\ Part of the Chemistry Commons

\section{Recommended Citation} \\ Hu, Wenhui; Ludwig, John; Pattengale, Brian; Yang, Sizhuo; Liu, Cunming; Zuo, Xiaobing; Zhang, Xiaoyi; and \\ Huang, Jier, "Unravelling the Correlation of Electronic Structure and Carrier Dynamics in CulnS2 \\ Nanoparticles" (2017). Chemistry Faculty Research and Publications. 976. \\ https://epublications.marquette.edu/chem_fac/976
}




\section{Authors}

Wenhui Hu, John Ludwig, Brian Pattengale, Sizhuo Yang, Cunming Liu, Xiaobing Zuo, Xiaoyi Zhang, and Jier Huang

This article is available at e-Publications@Marquette: https://epublications.marquette.edu/chem_fac/976 
Marquette University

e-Publications@Marquette

\section{Chemistry Faculty Research and Publications/College of Arts and Sciences}

This paper is NOT THE PUBLISHED VERSION; but the author's final, peer-reviewed manuscript. The published version may be accessed by following the link in th citation below.

Journal Of Physical Chemistry : C, Vol. 122, No. 1 (December 12, 2017): 974-980. DOI. This article is (C) American Chemical Society and permission has been granted for this version to appear in ePublications@Marquette. American Chemical Society does not grant permission for this article to be further copied/distributed or hosted elsewhere without the express permission from American Chemical Society.

\section{Unravelling the Correlation of Electronic Structure and Carrier Dynamics in CulnS 2 Nanoparticles}

Wenhui Hu

Department of Chemistry, Marquette University, Milwaukee, Wisconsin John Ludwig Department of Chemistry, Marquette University, Milwaukee, Wisconsin Brian Pattengale

Department of Chemistry, Marquette University, Milwaukee, Wisconsin Sizhuo Yang

Department of Chemistry, Marquette University, Milwaukee, Wisconsin Cunming Liu X-ray Science Division, Argonne National Laboratory, Argonne, Illinois Xiaobing Zuo X-ray Science Division, Argonne National Laboratory, Argonne, Illinois 


\section{Xiaoyi Zhang}

X-ray Science Division, Argonne National Laboratory, Argonne, Illinois

Jier Huang

Department of Chemistry, Marquette University, Milwaukee, Wisconsin

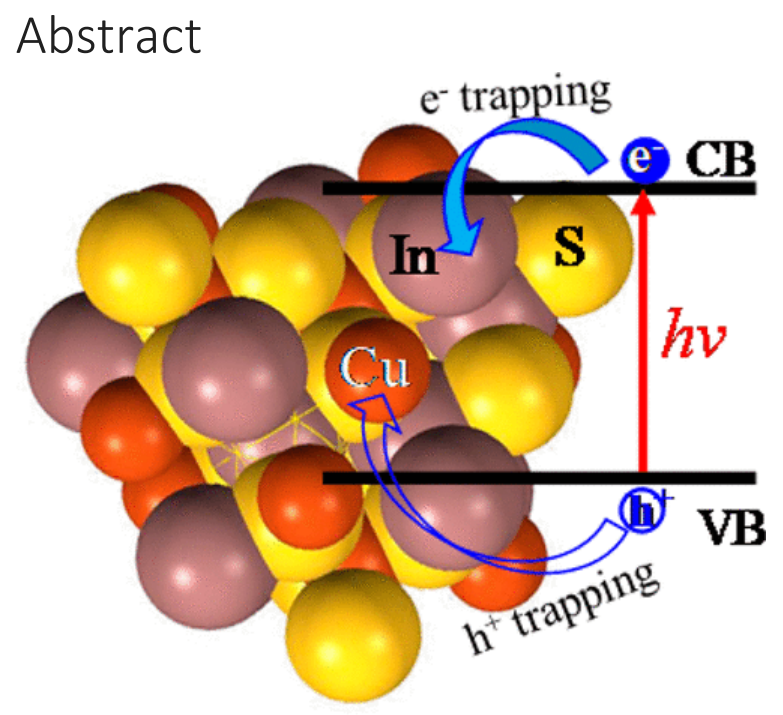

In this work, we report the direct correlation of photoinduced carrier dynamics and electronic structure of CulnS $_{2}$ (CIS) nanoparticles (NPs) using the combination of multiple spectroscopic techniques including steadystate X-ray absorption spectroscopy (XAS), optical transient absorption (OTA), and X-ray transient (XTA) absorption spectroscopy. XAS results show that CIS NPs contain a large amount of surface $\mathrm{Cu}$ atoms with $\ll$ fourcoordination, which is more severe in CIS NPs with shorter nucleation times, indicating the presence of more $\mathrm{Cu}$ defect states in CIS NPs with smaller size particles. Using the combination of OTA and XTA spectroscopy, we show that electrons are trapped at states with mainly In or $\mathrm{S}$ nature while holes are trapped in sites characteristic of $\mathrm{Cu}$. While there is no direct correlation of ultrafast trapping dynamics with NP nucleation time, charge recombination is significantly inhibited in CIS NPs with larger particles. These results suggest the key roles that $\mathrm{Cu}$ defect sites play in carrier dynamics and imply the possibility to control the carrier dynamics by controlling the surface structure at the Cu site in CIS NPs.

\section{Introduction}

Colloidal semiconductor nanocrystals are under intense investigation due to their wide range of applications including solar cells, light-emitting diodes, catalysis, and bioimaging.(1-3) However, most early works have focused on using semiconductors based on toxic elements such as $\mathrm{Cd}$ and $\mathrm{Pb},(4-7)$ which largely limits their practical applications. As a result, recent efforts have been geared toward low toxicity multinary nanocrystals such as copper indium sulfide (CIS). These nanocrystals possess tunable band structure and optical properties, which have led to their use in optoelectronics and biological applications. $(1,4)$ They have high extinction coefficient, emission quantum yield, and appropriate band gaps, which have rendered these nanocrystals desirable as light-harvesting and charge separation materials in photovoltaics and photocatalysis.(8-13)

As the functions of CIS in these applications are mainly dictated by their light-absorbing and emission behaviors, it is essential to develop a deep understanding of the excited state dynamics of CIS. Indeed, there are a handful of recent reports that have explored the excited state properties of CIS or CIS-based nanocrystals using timeresolved spectroscopic techniques.(14-17) For example, a few studies have reported the origins of the extremely 
long radiative lifetimes and large Stokes shift of CIS vs CdSe nanocrystals, which was attributed to the presence of Cu-related intragap emission center.(18-21) Other studies based on transient absorption spectroscopy have explained the multiple-component carrier cooling and recombination dynamics, which was assigned to the transition involving the band gap, sub-band gap, or surface trap states.(17, 19, 22-24) While these studies provide valuable information on the excited state properties of CIS nanocrystals, few efforts have been made to explore the correlation of these optical properties with their electronic structure, yet they are essential to fully understand the photophysical properties of CIS as a whole.

In this work, we report the direct correlation of carrier dynamics with electronic structure of CIS nanoparticles (NPs) using the combination of synchrotron-based X-ray absorption (XAS) and X-ray transient absorption (XTA) spectroscopies and optical transient absorption (OTA) spectroscopy. We found that CIS NPs contain large amount of surface $\mathrm{Cu}$ atoms without tetrahedral coordination, which likely serve as hole-trapping sites during the photoinduced trapping process. The surface structure of Cu site in CIS NPs can be controlled by the nucleation time during synthesis, where tetrahedral structure of Cu center is more developed in CIS NPs with longer nucleation time, which leads to longer electron-hole recombination time, suggesting the possibility to control the carrier dynamics by controlling the surface structure of CIS NPs. This study provides important insight into the correlation of carrier dynamics with surface structure of CIS NPs, which will facilitate rational design of CIS NPs toward their application in photovoltaic and light-emitting devices.

\section{Experimental Methods}

\section{Materials}

Copper(I) iodide (Cul, 98\%), indium(III) acetate $\left(\operatorname{In}\left(\mathrm{OOCCH}_{3}\right)_{3}, 99.99 \%\right.$ metals basis), 1-dodecanethiol (DDT, 98\%), acetone (HPLC grade, 99.5+\%), $n$-hexane (spectrophotometric grade, 95+\%), and toluene (anhydrous, 99.8\%) were purchased from Alfa Aesar (Tewksbury, MA).

\section{Synthesis of CIS NCS}

Following the published procedure,(18) $\mathrm{Cul}(382 \mathrm{mg}, 2 \mathrm{mmol}), \ln \left(\mathrm{OOCCH}_{3}\right)_{3}(580 \mathrm{mg}, 2 \mathrm{mmol})$, and DDT (10 mL) were mixed in a three-neck flask, degassed under vacuum for $5 \mathrm{~min}$, and then purged with $\mathrm{N}_{2}$ for $10 \mathrm{~min}$. The flask was heated to $120^{\circ} \mathrm{C}$ for $10 \mathrm{~min}$ to dissolve the reagents and then to $200^{\circ} \mathrm{C}$ for nucleation of the NPs. At the desired time point $(15,30$, or $60 \mathrm{~min})$, the flask was placed in a water bath to stop the growth of the NPs. The cooled samples were transferred to a centrifuge tube with $\sim 20 \mathrm{~mL}$ of acetone and centrifuged to isolate the sample after decanting the supernatant. The CIS NPs were then redispersed in toluene for further experimentation.

\section{Characterization}

Steady-state UV-visible absorption spectra were taken using an HP Agilent 8453 spectrophotometer. Steadystate emission spectra were measured using a Photon Technology International QuantaMaster 40 spectrofluorometer. All samples were degassed prior to emission measurement with $\mathrm{N}_{2}$ gas. A Rigaku MiniFlex II diffractometer with $\mathrm{Cu}$ K $\alpha$ radiation was used to collect X-ray diffraction (XRD) patterns. The samples were prepared by allowing $\mathrm{CuInS}_{2}$ /toluene solutions to dry in air on a frosted glass sample plate.

\section{Steady-State X-ray Absorption Spectroscopy (XAS)}

XAS measurements were performed at the beamline 12BM at the Advanced Photon Source, Argonne National Laboratory. The XAS spectra were collected at room temperature by fluorescence mode using a 13-element germanium solid-state detector. One ion chamber is placed before the sample and used as the incident X-ray 
flux reference signal. There are two ion chambers (second and third chambers) after the sample. The copper foil is placed between the second and third ion chambers and used for energy calibration and collecting copper metal spectrum.

\section{Small-Angle X-ray Scattering (SAXS)}

The size and distribution of CIS NPs were determined by SAXS which was measured at beamline 12ID-B at the Advanced Photon Source, Argonne National Laboratory. The wavelength, $\lambda$, of X-ray radiation was set as 0.886

$\AA$ A. Scattered X-ray intensities were measured using a Pilatus $2 \mathrm{M}$ detector. The sample-to-detector distance was set such that the detecting range of momentum transfer $q(=4 \pi \sin \theta / \lambda$, where $2 \theta$ is the scattering angle) was $0.006-0.90 \AA^{-1}$. A flow cell that is made of a cylindrical quartz capillary with a diameter of $1.5 \mathrm{~mm}$ and a wall of $10 \mu \mathrm{m}$ was used for SAXS measurements. To obtain good signal-to-noise ratio, 20 scattering images were collected for each sample or solvent. The 2-D scattering images were converted to 1-D SAXS $(I(q)$ vs $q)$ curves through azimuthally averaging after solid angle correction and then normalizing with the intensity of the transmitted X-ray beam flux, using a software package developed for the beamline. After subtraction of the solvent background, the SAXS profiles were fit using Irena package $\underline{25)}$ with the assumption of spherical particle shape and log-normal size distribution.

\section{Time-Resolved Optical Absorption Spectroscopy (OTA)}

The femtosecond OTA setup is based on a regenerative amplified Ti-sapphire laser system (Solstice, $800 \mathrm{~nm}$, $<100 \mathrm{fs}$ fwhm, $3.5 \mathrm{~mJ} /$ pulse, $1 \mathrm{kHz}$ repetition rate). The tunable pump $(235-1100 \mathrm{~nm})$, chopped at $500 \mathrm{~Hz}$, is generated in TOPAS (Light Conversion) from $75 \%$ of the split output from the Ti-sapphire laser. The tunable UVvisible probe pulses are generated from the other $25 \%$ of the Ti-sapphire output through white light generation in a sapphire (430-750 $\mathrm{nm}$ ) window on a translation stage. The femtosecond OTA measurements were performed in a Helios ultrafast spectrometer (Ultrafast Systems LLC). The energy of pump pulse used for the measurements was $28 \mu \mathrm{J} / \mathrm{cm}^{2}$. The sample was placed in a cuvette with a path length of $2 \mathrm{~mm}$, which was continuously stirred during measurements to avoid sample degradation.

\section{Time-Resolved X-ray Absorption Spectroscopy (XTA)}

XTA was performed at beamline 11ID-D, Advanced Photon Source (APS), at Argonne National Laboratory. The sample was excited with $400 \mathrm{~nm}, 100 \mathrm{fs}$ laser pulse that was generated from the second harmonic of Ti:sapphire regenerative amplified laser operating at $10 \mathrm{kHz}$ repetition rate. The experiment was carried out under the hybrid-timing mode where an intense X-ray pulse was used as the probe pulse. This intense pulse (117 ps, 271.5 $\mathrm{kHz}$ ) contains $16 \%$ of the total average photon flux and was separated in time from other weak X-ray pulses. Two avalanche photodiodes (APD) were positioned at a $90^{\circ}$ angle on both sides of the incident X-ray beam to collect the $\mathrm{X}$-ray fluorescence signals from $\mathrm{Cu}-\mathrm{K}$ edge absorption. The $\mathrm{CIS} /$ toluene solution was flowed through a stainless steel tube and formed a free jet (600 $\mu \mathrm{m}$ diameter) in the sample chamber. Custom-designed soller slit/Ni filter combination was placed at a specific distance between the sample and the detectors. The X-ray fluorescence photons from the synchronized X-ray pulse at $110 \mathrm{ps}$ after the laser pulse excitation were used to build the laser-on spectrum. The fluorescence signals averaged over 20 bunches before laser pulse were used to construct the ground-state spectrum.

\section{Results and Discussion}

The bulk structure of CIS NPs synthesized under three different nucleation times was first characterized using Xray diffraction (XRD). As shown in Figure 1a, the XRD patterns of these NPs show three main peaks with $2 \theta$ values of $28.0^{\circ}, 46.5^{\circ}$, and $54.9^{\circ}$, which are consistent with literature values and can be assigned to the (112), 
$(204) /(220)$, and (116)/(312) planes of tetragonal chalcopyrite structure of CIS, respectively.(22, 26-28)Figure 1b shows the UV-visible absorption and emission spectra (inset) of the CIS NPs synthesized under different nucleation times. These UV-visible spectra show broad absorption with the lack of a well-defined excitonic peak, which are commonly seen in CIS NPs and result from the inhomogeneity of the band gap states.(12, 21, 29) The presence of multiple donor and trap states within the band gap leads to the formation of a broad shoulder. Meanwhile, the shoulders of these spectra as well as their corresponding emission spectra (inset of Figure 1b) show red shift with increasing nucleation time, which can be attributed to the reduction of quantum confinement effects from the increase of particle dimensions.(23) The shape and size distributions of CIS NPS were evaluated by solution small-angle X-ray scattering (SAXS) measured at 12ID-B of the Advanced Photon Source at Argonne National Laboratory. As shown in Figure $1 \mathrm{c}$ and $\underline{1} \mathrm{~d}$, the scattering profiles of these samples could all be fit with spherical particle model $(30)$ with mean radius of $9.8,12.2$, and $14.7 \AA$ for 15,30 , and 60 min, respectively. The sizes of these CIS NPs are smaller than the Bohr exciton radius $(3.8 \mathrm{~nm})$ of bulk $\mathrm{CIS},(31$, $\underline{32)}$ indicating a strong quantum confinement effect, which explains the strong dependence of optical properties on sizes (Figure $1 b$ ).
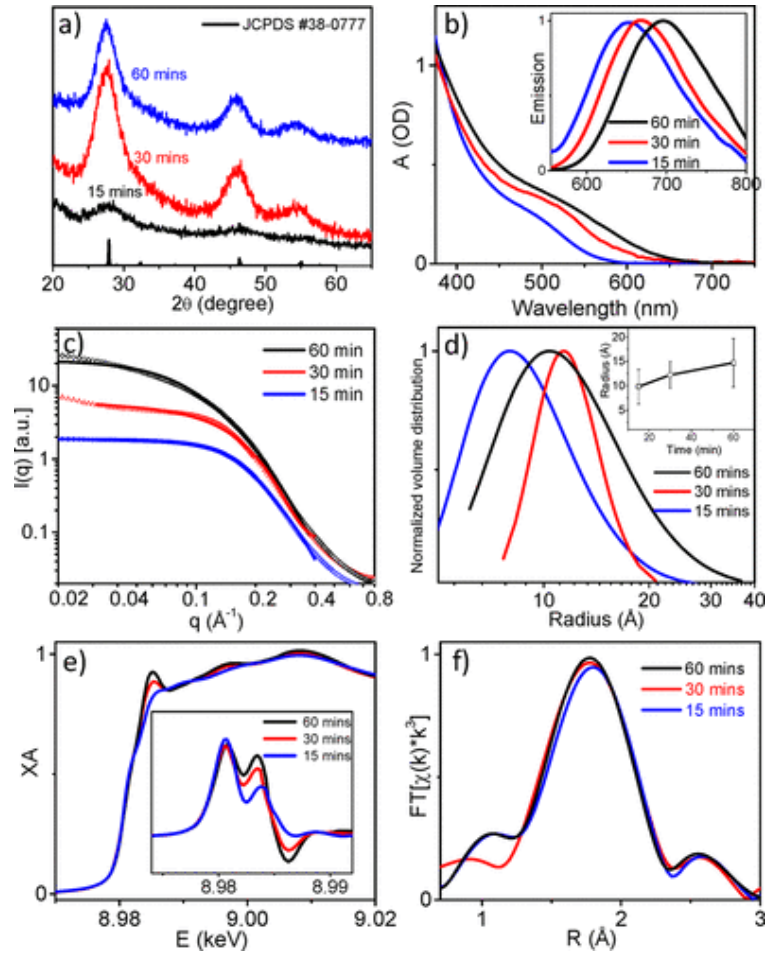

Figure 1. XRD patterns (a), UV-visible absorption spectra (b), and emission spectra (inset of b) of CIS NPs synthesized with nucleation time 15, 30, and $60 \mathrm{~min}$. (c) SAXS data (symbols) and fit (solid lines) using spherical particle model whose size follows log-normal distribution. (d) Particle radius distribution yielded from the SAXS data fitted under spherical shape assumption. Comparison of XANES spectra (e) and Fourier-transformed EXAFS spectra (f) of CIS NPs synthesized with nucleation time 15, 30, and $60 \mathrm{~min}$. The inset in (e) shows the comparison of their first-derivative spectra.

In addition to the bulk structure, the effect of the nucleation time on the local structure was examined using Xray absorption spectroscopy (XAS). Figure 1e shows the normalized X-ray absorption near-edge structure (XANES) spectra of CIS NPs at Cu K-edge. All three spectra show a peak at $8.986 \mathrm{keV}$ and a broad transition from 8.99 to $9.01 \mathrm{keV}$. These features have been previously observed in chalcopyrite NPs and can be assigned to 1s$4 p_{z}$ and $1 s-4 p_{x y}$ transitions of $\mathrm{Cu}^{1+}$, respectively. $(33,34)$ The $\mathrm{Cu}^{1+}$ oxidation state was further supported by the 
absence of the pre-edge feature at $\sim 8.98 \mathrm{keV}$ (inset of Figure 1e), which represents the quadrupole 1s-3d transition of $\mathrm{Cu}$ center and is only allowed if there is $\mathrm{Cu}^{2+}$ with $3 \mathrm{~d}^{9}$ configuration.(33) Meanwhile, the edge energy shows negligible shift among these samples (inset of Figure 1e), suggesting that the oxidation state of $\mathrm{Cu}^{1+}$ retains regardless of nucleation time. However, notable differences were observed in the peak corresponding to $1 \mathrm{~s}-4 \mathrm{p}_{z}$ transition, where the peak becomes sharper in the spectra of the NPs with longer nucleation time. It has been shown that the sharp nature of $1 s-4 p_{z}$ transition is an indication of tetrahedrally coordinated $\mathrm{Cu}$, while a smoother feature is characteristic of triangular coordination. $(34,35)$ These results suggest that the tetrahedral structure of $\mathrm{Cu}^{1+}$ is more developed in the $60 \mathrm{~min}$ sample than in samples with shorter nucleation times.

Additional difference was observed among these samples in their extended X-ray absorption fine structure (EXAFS) spectra in R-space, where the intensity of the peak representing $\mathrm{Cu}-\mathrm{S}$ shows slight increase with increasing nucleation time (Figure 1f). It has been shown that the increase of peak intensity is associated with either the increasing coordination number or the decrease of disorder around the metal center.(36) To gain more insight into these two possibilities, we quantitatively analyzed the local structure of these NPs through fitting EXAFS data using IFEFF modeling. Figure 2 shows the best fits to the EXAFS spectra in both R-and k-space for all three samples. The resulting fitting parameters are listed in Table 1. While the $\mathrm{Cu}-\mathrm{S}$ bond distance shows negligible change among three samples, notable increase of coordination number of $\mathrm{Cu}$ and slight increase of Debye-Waller factor were observed with nucleation time, suggesting that the enhanced peak intensity in NPs with nucleation time (Figure 1e) is primarily due to the increase of average coordination number at Cu center. This is consistent with the XANES results, where the CIS NPs with longer nucleation time contain more fourcoordinated tetrahedral $\mathrm{Cu}$ centers than those with shorter nucleation time. Furthermore, it is noted that the average coordination number of $\mathrm{Cu}$ center in all samples is $\sim 2$, which is only half of the expected coordination number in a tetrahedrally coordinated $\mathrm{Cu}$ center. This has been observed previously in similar semiconductor nanoparticles and can be attributed to the presence of a large number of vacancy defects at surface Cu centers, which do not possess tetrahedron. $(37,38)$ These results together suggest that a larger portion of surface $\mathrm{Cu}$ atoms with nontetrahedral coordination is present in smaller CIS NPs synthesized under shorter nucleation times, which leads to the less developed tetrahedral $\mathrm{Cu}$ center and smaller average coordination number at $\mathrm{Cu}$ center uncovered by XAS. The presence of a large percentage of surface $\mathrm{Cu}$ atoms in CIS NPs also well explains the observed poorly defined excitonic peak and broad shoulder in UV-visible spectra, large Stokes shift, as well as the presence of multiple trap states within CIS band gap. 

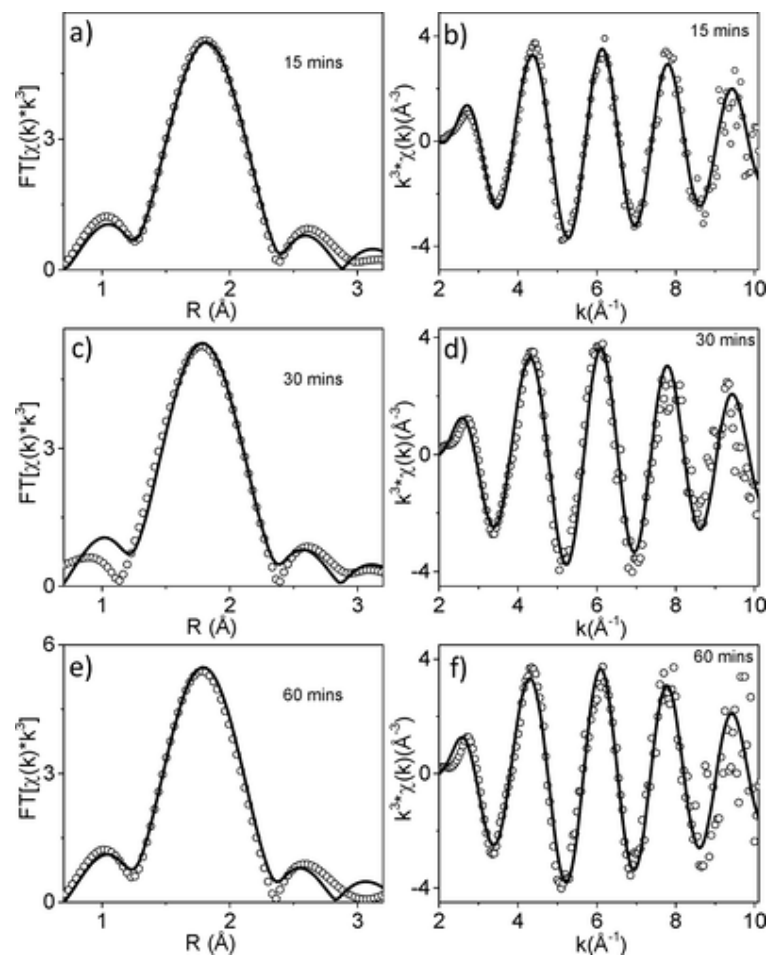

Figure 2. XAFS spectra (open dot) and the best fit (solid line) of CIS NPs in R-space and k-space with nucleation times 15 min $(a, b), 30 \mathrm{~min}(c, d)$, and $60 \mathrm{~min}(e, f)$, respectively.

Table 1. XAFS Fitting Parameters for CIS NPs

\begin{tabular}{|c|c|c|c|c|c|c|c|c|c|}
\hline & $15 \mathrm{~min}$ & & & $30 \mathrm{~min}$ & & & $60 \mathrm{~min}$ & & \\
\hline $\begin{array}{l}\text { vecto } \\
r\end{array}$ & $N$ & $R(\AA)$ & $\begin{array}{l}\sigma^{2}\left(10^{-}\right. \\
\left.{ }^{3} \AA^{2}\right)\end{array}$ & $N$ & $R(\AA)$ & $\sigma^{2}\left(\AA^{2}\right)$ & $N$ & $R(\AA)$ & $\sigma^{2}\left(\AA^{2}\right)$ \\
\hline $\mathrm{Cu}-\mathrm{S}$ & $\begin{array}{l}2.05 \pm 0 \\
18\end{array}$ & $\begin{array}{l}2.27 \pm 0 \\
02\end{array}$ & $6.7 \pm 1.4$ & $\begin{array}{l}2.24 \pm 0 \\
33\end{array}$ & $\begin{array}{l}2.28 \pm 0 \\
02\end{array}$ & $\begin{array}{l}7.4 \pm 2 . \\
3\end{array}$ & $\begin{array}{l}2.36 \pm 0 \\
21\end{array}$ & $\begin{array}{l}2.28 \pm 0 \\
02\end{array}$ & $\begin{array}{l}8.0 \pm 1 . \\
4\end{array}$ \\
\hline
\end{tabular}

To reveal the effect of surface defects on the photophysical properties of CIS NPs, we examined its carrier dynamics using femtosecond transient optical absorption (fs-OTA) spectroscopy. Figure 3 shows the fs-OTA spectra of these samples following $480 \mathrm{~nm}$ excitation. All spectra (Figure $3 a-c$ ) were featured by a prominent ground-state bleach (GSB) band, which shifts to longer wavelength with nucleation time (Figure $3 \mathrm{~d}$ ), consistent with their UV-visible absorption spectra (Figure 1b). Meanwhile, broad absorption bands were observed on both sides of the GSB for each sample. Similar absorption features have been observed previously and can be assigned to the photoinduced electron signals as these features are quenched upon the addition of an electron acceptor, i.e., methyl viologen hydrate.(39) 

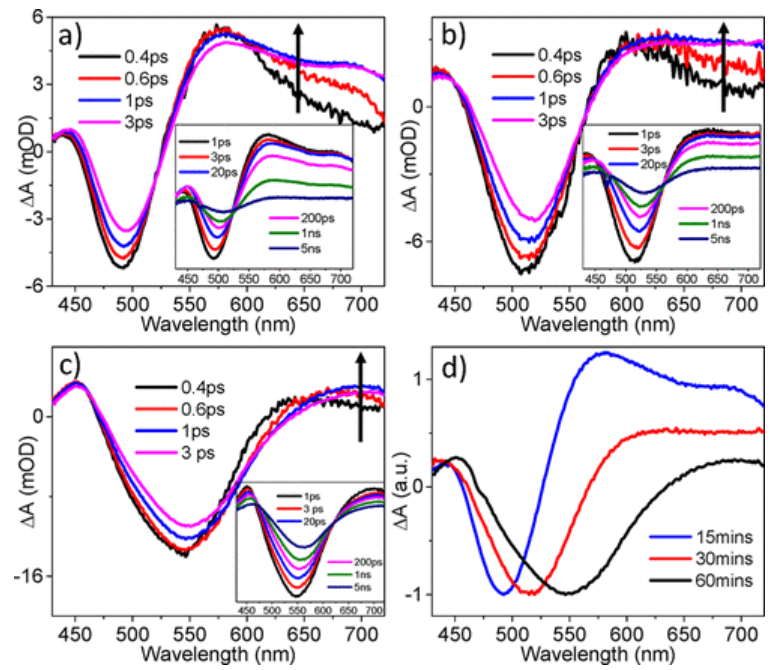

Figure 3. Femtosecond OTA spectra of CIS NPs with $15 \mathrm{~min}$ (a), $30 \mathrm{~min}$ (b), and $60 \mathrm{~min}$ (c) nucleation time following $480 \mathrm{~nm}$ excitation. (d) The comparison of 1 ps TA spectra of CIS NPs at different nucleation times. The insets show the late time spectra.

To further analyze the carrier dynamics of CIS NPs, we compared the kinetic traces of GSB and photoinduced electron signals among the samples with different nucleation times. As shown in Figure $4 a-c$, the kinetic traces of electron absorption dynamics are strongly dependent on probe wavelengths, characteristic of carrier-trapping process, $(33,40,41)$ indicating that electron-trapping process occurs in each sample. The kinetic traces at different probe wavelength for each sample can be adequately fit by a four-exponential function, including an ultrafast rising/decay time constant followed by three decay components. We attributed the ultrafast subpicosecond component for all samples to electron-trapping process, which remains relatively similar among the three samples as shown in Table 2. We attributed the three decay components to electron-hole recombination which was fixed during the fitting process according to the rationale that the late time decay kinetics at different wavelengths remain similar. While there is no clear dependence of electron-trapping time on sample nucleation time, notable difference was observed in the GSB recovery kinetics. As shown in Figure $4 \mathrm{~d}$, the GSB recovery (inverted) slows down with nucleation time, suggesting a slower electron-hole recombination process. Due to the presence of $\gg 5$ ns time constant which is beyond the fs-OTA time window, we are not able to quantitatively determine the charge recombination time. Instead, half-recovery time $\left(\tau_{1 / 2}\right)$, when the amplitude of GSB recovers to its half, was used to evaluate the charge recombination time. The estimated $\tau_{1 / 2}$ was $15.2,169.9$, and 5033 ps for 15,30 , and 60 min sample, respectively, indicating the elongated electronhole recombination time in CIS NPs synthesized using longer nucleation time. 

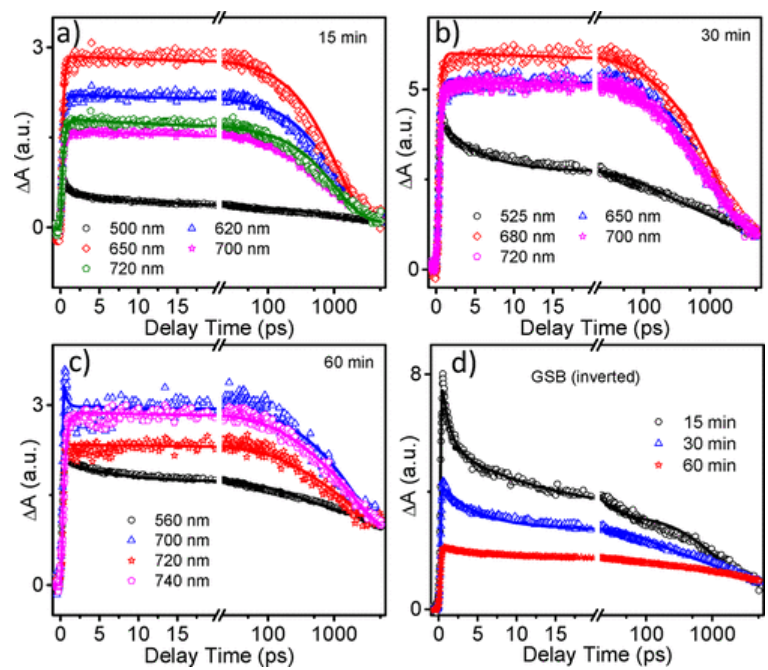

Figure 4. Comparison of OTA kinetic traces of CIS NPs at various probe wavelengths for samples with 15 min (a), 30 min (b), and $60 \mathrm{~min}$ (c) nucleation time following $480 \mathrm{~nm}$ excitation. (d) The comparison of ground-state bleach recovery kinetics (inverted) for 15, 30, and 60 min samples. These kinetic traces are normalized at $5 \mathrm{~ns}$ for better comparison.

Table 2. Fitting Parameters for TA Kinetics of CIS NPs ('Rising Component in a Multiexponential Function)

\begin{tabular}{|c|c|c|c|c|c|c|c|c|c|}
\hline $\begin{array}{l}\text { nucleation time, } \\
\text { min }\end{array}$ & $\begin{array}{l}\text { probe, } \\
\mathrm{nm}\end{array}$ & $\tau_{1}, p s$ & $\begin{array}{l}A_{1}, \\
\%\end{array}$ & $\tau_{2}, p s$ & $\begin{array}{l}A_{2}, \\
\%\end{array}$ & $\tau_{3}, p s$ & $\begin{array}{l}A_{3}, \\
\%\end{array}$ & $\begin{array}{l}\tau_{4}, \\
\text { ns }\end{array}$ & $\begin{array}{l}A_{4}, \\
\%\end{array}$ \\
\hline \multirow[t]{5}{*}{15} & 500 & $1.09 \pm 0.13$ & 30.5 & $\begin{array}{l}13.9 \pm 3 \\
7\end{array}$ & 29.1 & $\begin{array}{l}1040 \pm 2 \\
7\end{array}$ & 27.4 & $\gg 5$ & 13 \\
\hline & 620 & $\begin{array}{l}r 0.23 \pm 0.0 \\
1\end{array}$ & 100 & & 2.0 & & 93.5 & & 4.5 \\
\hline & 650 & $\begin{array}{l}r 0.23 \pm 0.0 \\
1\end{array}$ & 100 & & 1.9 & & 95.2 & & 2.9 \\
\hline & 700 & $\begin{array}{l}r 0.29 \pm 0.0 \\
1\end{array}$ & 100 & & 6.1 & & 88.1 & & 5.8 \\
\hline & 720 & $\begin{array}{l}r 0.32 \pm 0.0 \\
1\end{array}$ & 100 & & 7.9 & & 87.5 & & 4.9 \\
\hline \multirow[t]{5}{*}{30} & 525 & $4.58 \pm 0.17$ & 33 & $135 \pm 4.5$ & 17.8 & $\begin{array}{l}1190 \pm 4 \\
3\end{array}$ & 23.9 & $\gg 5$ & 25.4 \\
\hline & 650 & $\begin{array}{l}r 0.27 \pm 0.0 \\
1\end{array}$ & 100 & & 5.0 & & 73.3 & & 16.7 \\
\hline & 680 & $\begin{array}{l}r 0.25 \pm 0.0 \\
1\end{array}$ & 100 & & 7.9 & & 75.5 & & 16.6 \\
\hline & 700 & $\begin{array}{l}r 0.35 \pm 0.0 \\
1\end{array}$ & 100 & & 10.8 & & 70.7 & & 18.5 \\
\hline & 720 & $\begin{array}{l}r 0.31 \pm 0.0 \\
1\end{array}$ & 100 & & 13.2 & & 67.8 & & 19.0 \\
\hline \multirow[t]{3}{*}{60} & 560 & $5.79 \pm 0.19$ & 16.1 & $237 \pm 7.8$ & 14.1 & $\begin{array}{l}1990 \pm 7 \\
6\end{array}$ & 22.2 & $\gg 5$ & 47.4 \\
\hline & 700 & $0.35 \pm 0.01$ & 19.6 & & 7.37 & & 50 & & 22.9 \\
\hline & 720 & $\begin{array}{l}r 0.14 \pm 0.0 \\
1\end{array}$ & 100 & & 15.1 & & 47.1 & & 37.8 \\
\hline
\end{tabular}




\begin{tabular}{|l|l|l|l|l|l|l|l|l|l|}
\hline & 740 & $\begin{array}{l}\text { r } 0.38 \pm 0.0 \\
1\end{array}$ & 100 & & 14.7 & & 54.8 & & 30.5 \\
\hline
\end{tabular}

In addition to the carrier dynamics, the nature of trap states was investigated by probing the oxidation state change at Cu center using time-resolved X-ray absorption spectroscopy (XTA). Figure 5 shows the XANES spectrum of CIS NPs with 60 min nucleation time at Cu K-edge without laser excitation (laser-off spectrum). This spectrum resembles the XANES spectrum in Figure 1e, representing the steady-state XANES spectrum of CIS NPs. Also shown in Figure $5 \mathrm{a}$ is the tranisent XANES signal, presented as the difference XANES spectrum obtained by subtracting the steady-state XANES spectrum from the XANES spectrum with laser excitation at 110 ps (laser-on spectrum). A prominent negative feature at $8.983 \mathrm{keV}$ in the difference spectrum indicates that the Cu transition edge shifts to higher energy, suggesting the oxidation at $\mathrm{Cu}$ center following photoexcitation.(42) This assignment was further confirmed by the small positive feature at $8.98 \mathrm{keV}$ which corresponds to quadrupole $1 \mathrm{~s}-3 \mathrm{~d}$ transition. Because $1 \mathrm{~s}-3 \mathrm{~d}$ transition is forbidden in $\mathrm{Cu}^{1+}$ with $3 \mathrm{~d}(10)$ configuration but is possible in $\mathrm{Cu}^{2+}$ center, the appearance of this transition indicates the oxidation of $\mathrm{Cu}$ center. Because the full-width at half-maximum (fwhm) of X-ray probe is $\sim 117 \mathrm{ps}$ and electron-trapping process occurs on a subpicosecond time scale revealed by fs-OTA, the XTA spectrum collected at $110 \mathrm{ps}$ after laser excitation represents the spectrum when electron-trapping process has completed. As a result, the observed oxidation at $\mathrm{Cu}$ center indicates that the electrons are removed from $\mathrm{Cu}$ site and trapped at the surrounding sites, such as In or S sites ( $\underline{\text { Figure } 5}$ b), implying that holes are located at sites characteristic of $\mathrm{Cu}$. We are unsure whether the holes at $\mathrm{Cu}$ center are located in valence band or trap states. However, due to the presence of large amount of surface $\mathrm{Cu}$ atoms with defects, as indicated by XAS, we believe that trapped holes play a major role in the oxidation of $\mathrm{Cu}$ center, though holes at valence band cannot be excluded.
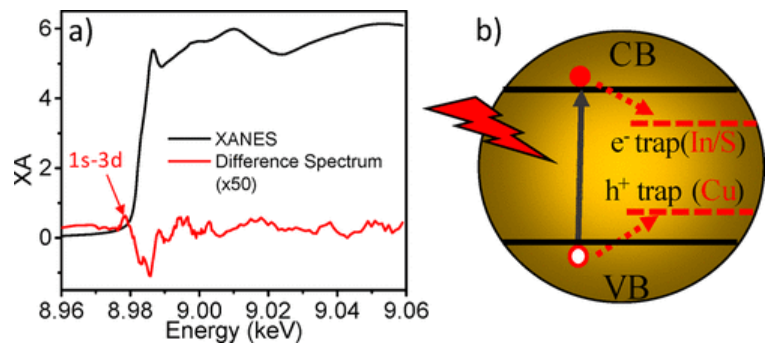

Figure 5. (a) XANES spectrum (black plot) and difference XANES spectrum (red plot) of CIS NPs with 60 min nucleation time at Cu K-edge. The difference XANES spectrum was obtained after subtracting the XANES spectrum without laser excitation from the XANES spectrum collected at 110 ps after laser excitation. (b) Scheme illustration of carrier dynamics in CIS NPs following photoexcitation.

\section{Conclusions}

In summary, we have examined the correlation of the photoinduced carrier dynamics in CIS NPs with their electronic structure using the combination of multiple spectroscopic techniques. Using steady-state and timeresolved XAS spectroscopy, we show that CIS NPs contain a large portion of surface $\mathrm{Cu}$ atoms that do not have tetrahedral structure, which serve as hole-trapping sites. The structure of surface $\mathrm{Cu}$ atoms in CIS NPs can be controlled by nucleation time during synthesis, where the tetrahedral structure at Cu center is more developed in NPs with longer nucleation time (larger size), resulting in longer electron-hole recombination time. These results indicate the possibility to inhibit carrier recombination through controlling the electronic structure of surface $\mathrm{Cu}$ atoms, providing important insight in fundamental understanding of carrier dynamics in CIS NPs and facilitating their potential application in photovoltaics and light-emitting devices. 
The authors declare no competing financial interest.

\section{Acknowledgment}

This work was supported by National Science Foundation (DMR-1654140) and ACS-PRF (57503-DNI6). Use of the Advanced Photon Source in Argonne National Laboratory was supported by the U.S. Department of Energy, Office of Science, Office of Basic Energy Sciences, under Award No. DE-AC02-06CH11357.

\section{References}

1 Talapin, D. V.; Lee, J. S.; Kovalenko, M. V.; Shevchenko, E. V. Prospects of Colloidal Nanocrystals for Electronic and Optoelectronic Applications Chem. Rev. 2010, 110, 389-458DOI: 10.1021/cr900137k

$\underline{2}$ Kamat, P. V. Quantum Dot Solar Cells. Semiconductor Nanocrystals as Light Harvesters J. Phys. Chem. C 2008, 112, 18737-18753DOI: 10.1021/jp806791s

$\underline{\mathbf{3}}$ Scholes, G. D. Controlling the Optical Properties of Inorganic Nanoparticles Adv. Funct. Mater. 2008, 18, 1157-1172DOI: 10.1002/adfm.200800151

$\underline{4}$ Bruchez, M., Jr.; Moronne, M.; Gin, P.; Weiss, S.; Alivisatos, A. P. Semiconductor Nanocrystals as Fluorescent Biological Labels Science 1998, 281, 2013-2016DOI: 10.1126/science.281.5385.2013

$\underline{5}$ Klimov, V. I.; Ivanov, S. A.; Nanda, J.; Achermann, M.; Bezel, I.; McGuire, J. A.; Piryatinski, A. Single-Exciton Optical Gain in Semiconductor Nanocrystals Nature 2007, 447, 441-446DOI: 10.1038/nature05839

6ZZhu, H. M.; Song, N. H.; Rodriguez-Cordoba, W.; Lian, T. Q. Wave Function Engineering for Efficient Extraction of up to Nineteen Electrons from One CdSe/CdS Quasi-Type li Quantum Dot J. Am. Chem. Soc. 2012, 134, 4250-4257DOI: 10.1021/ja210312s

Z Han, Z. J.; Qiu, F.; Eisenberg, R.; Holland, P. L.; Krauss, T. D. Robust Photogeneration of H-2 in Water Using Semiconductor Nanocrystals and a Nickel Catalyst Science 2012, 338, 1321-1324DOI: 10.1126/science. 1227775

$\underline{8}$ Li, L.; Coates, N.; Moses, D. Solution-Processed Inorganic Solar Cell Based on in Situ Synthesis and Film Deposition of CulnS 2 Nanocrystals J. Am. Chem. Soc. 2010, 132, 22- 23DOI: 10.1021/ja908371f

9 Chirila, A.; Reinhard, P.; Pianezzi, F.; Bloesch, P.; Uhl, A. R.; Fella, C.; Kranz, L.; Keller, D.; Gretener, C.; Hagendorfer, H.Potassium-Induced Surface Modification of $\mathrm{Cu}(\mathrm{In}, \mathrm{Ga}) \mathrm{Se}_{2}$ Thin Films for HighEfficiency Solar Cells Nat. Mater. 2013, 12, 1107-1111DOI: 10.1038/nmat3789

10 Weil, B. D.; Connor, S. T.; Cui, Y. CulnS 2 Solar Cells by Air-Stable Ink Rolling J. Am. Chem. Soc. 2010, 132, 6642-6643DOI: 10.1021/ja1020475

$\underline{11}$ Li, T. L.; Teng, H. S. Solution Synthesis of High-Quality CulnS ${ }_{2}$ Quantum Dots as Sensitizers for $\mathrm{TiO}_{2}$ Photoelectrodes J. Mater. Chem. 2010, 20, 3656- 3664DOI: 10.1039/b927279h

12 Zhong, H. Z.; Lo, S. S.; Mirkovic, T.; Li, Y. C.; Ding, Y. Q.; Li, Y. F.; Scholes, G. D. Noninjection Gram-Scale Synthesis of Monodisperse Pyramidal CulnS 2 Nanocrystals and Their Size-Dependent Properties ACS Nano 2010, 4, 5253- 5262DOI: 10.1021/nn1015538

13 Sandroni, M.; Wegner, K. D.; Aldakov, D.; Reiss, P. Prospects of Chalcopyrite-Type Nanocrystals for Energy Applications ACS Energy Lett. 2017, 2, 1076- 1088DOI: 10.1021/acsenergylett.7b00003

14 Nam, D. E.; Song, W. S.; Yang, H. Noninjection, One-Pot Synthesis of Cu-Deficient CulnS $2 / Z n S$ Core/Shell Quantum Dots and Their Fluorescent Properties J. Colloid Interface Sci. 2011, 361, 491-496DOI: 10.1016/j.jcis.2011.05.058 
$\underline{15}$ Castro, S. L.; Bailey, S. G.; Raffaelle, R. P.; Banger, K. K.; Hepp, A. F. Synthesis and Characterization of Colloidal $\mathrm{CulnS}_{2}$ Nanoparticles from a Molecular Single-Source Precursor J. Phys. Chem.

B 2004, 108, 12429- 12435DOI: 10.1021/jp049107p

16 Wang, X.; Liang, Z. R.; Xu, X. Q.; Wang, N.; Fang, J.; Wang, J. X.; Xu, G. A High Efficient Photoluminescence ZnCu-In-S/ZnZ Quantum Dots with Long Lifetime J. Alloys Compd. 2015, 640, 134- 140DOI: 10.1016/j.jallcom.2015.03.249

17 Leach, A. D. P.; Macdonald, J. E. Optoelectronic Properties of CulnS 2 Nanocrystals and Their Origin J. Phys. Chem. Lett. 2016, 7, 572- 583DOI: 10.1021/acs.jpclett.5b02211

18 Li, L. A.; Pandey, A.; Werder, D. J.; Khanal, B. P.; Pietryga, J. M.; Klimov, V. I. Efficient Synthesis of Highly Luminescent Copper Indium Sulfide-Based Core/Shell Nanocrystals with Surprisingly Long-Lived Emission J. Am. Chem. Soc. 2011, 133, 1176-1179DOI: 10.1021/ja108261h

19 Bose, R.; Ahmed, G. H.; Alarousu, E.; Parida, M. R.; Abdelhady, A. L.; Bakr, O. M.; Mohammed, O. F. Direct Femtosecond Observation of Charge Carrier Recombination in Ternary Semiconductor Nanocrystals: The Effect of Composition and Shelling J. Phys. Chem. C 2015, 119, 3439-3446DOI: 10.1021/acs.jpcc.5b00204

20 Nam, D. E.; Song, W. S.; Yang, H. Facile, Air-Insensitive Solvothermal Synthesis of Emission-Tunable Cuins2/Zns Quantum Dots with High Quantum Yields J. Mater. Chem. 2011, 21, 18220-18226DOI: 10.1039/c1jm12437d

21 Zhong, H. Z.; Zhou, Y.; Ye, M. F.; He, Y. J.; Ye, J. P.; He, C.; Yang, C. H.; Li, Y. F. Controlled Synthesis and Optical Properties of Colloidal Ternary Chalcogenide CulnS 2 Nanocrystals Chem. Mater. 2008, 20, 6434-6443DOI: 10.1021/cm8006827

22 Jara, D. H.; Stamplecoskie, K. G.; Kamat, P. V. Two Distinct Transitions in $\mathrm{Cu}_{\mathrm{x}} \mathrm{InS} \mathrm{S}_{2}$ Quantum Dots. Bandgap Versus Sub-Bandgap Excitations in Copper-Deficient Structures J. Phys. Chem. Lett. 2016, 7, 1452-1459DOI: 10.1021/acs.jpclett.6b00571

23 Debnath, T.; Maiti, S.; Maity, P.; Ghosh, H. N. Subpicosecond Exciton Dynamics and Biexcitonic Feature in Colloidal CulnS 2 Nanocrystals: Role of In-Cu Antisite Defects J. Phys. Chem. Lett. 2015, 6, 3458- 3465DOI: 10.1021/acs.jpclett.5b01767

24 Halpert, J. E.; Morgenstern, F. S. F.; Ehrler, B.; Vaynzof, Y.; Credgington, D.; Greenham, N. C. Charge Dynamics in Solution-Processed Nanocrystalline CulnS 2 Solar Cells ACS Nano 2015, 9, 5857- 5867DOI: 10.1021/acsnano.5b00432

25 Ilavsky, J.; Jemian, P. R. Irena: Tool Suite for Modeling and Analysis of Small-Angle Scattering J. Appl. Crystallogr. 2009, 42, 347-353DOI: 10.1107/S0021889809002222

26 Panthani, M. G.; Akhavan, V.; Goodfellow, B.; Schmidtke, J. P.; Dunn, L.; Dodabalapur, A.; Barbara, P. F.; Korgel, B. A. Synthesis of CulnS 2 , CulnSe, and $\mathrm{Cu}\left(\ln _{x} \mathrm{Ga}_{1-x}\right) \mathrm{Se}_{2}$ (Cigs) Nanocrystal "Inks" for Printable Photovoltaics J. Am. Chem. Soc. 2008, 130, 16770- 16777DOI: 10.1021/ja805845q

$\underline{27}$ Zhou, Y.; Hu, W.; Ludwig, J.; Huang, J. Exceptionally Robust CulnS $2 /$ Zns Nanoparticles as Single Component Photocatalysts for $\mathrm{H}_{2}$ Evolution J. Phys. Chem. C 2017, 121, 19031- 19035DOI: 10.1021/acs.jpcc.7b05241

$\underline{28}$ Jara, D. H.; Yoon, S. J.; Stamplecoskie, K. G.; Kamat, P. V. Size-Dependent Photovoltaic Performance of CulnS $_{2}$ Quantum Dot-Sensitized Solar Cells Chem. Mater. 2014, 26, 7221- 7228DOI: $10.1021 / \mathrm{cm} 5040886$

29 Xie, R. G.; Rutherford, M.; Peng, X. G. Formation of High-Quality I-III-Vi Semiconductor Nanocrystals by Tuning Relative Reactivity of Cationic Precursors J. Am. Chem. Soc. 2009, 131, 5691-5697DOI: 10.1021/ja9005767 
30 Tang, Y.; Pattengale, B.; Ludwig, J.; Atifi, A.; Zinovev, A. V.; Dong, B.; Kong, Q. Y.; Zuo, X. B.; Zhang, X.

Y.; Huang, J. Direct Observation of Photoinduced Charge Separation in Ruthenium

Complex/Ni(OH) 2 Nanoparticle Hybrid Sci. Rep. 2016, 5, 18505DOI: 10.1038/srep18505

$31 \mathrm{Ho}, \mathrm{C}$. H. Temperature Dependent Crystal-Field Splitting and Band-Edge Characteristic in $\mathrm{Cu}\left(\mathrm{Al}_{\mathrm{x}} \mathrm{In}_{1-\mathrm{x}}\right) \mathrm{S}_{2}(0 \leq \mathrm{X} \leq$

1) Series Solar Energy Materials J. Electrochem. Soc. 2011, 158, H554- H560DOI: 10.1149/1.3567534

32 Venkatram, N.; Batabyal, S. K.; Tian, L.; Vittal, J. J.; Ji, W. Shape-Dependent Nonlinear Absorption and

Relaxation in CulnS 2 Nanocrystals Appl. Phys. Lett. 2009, 95, 201109-1- 201109-3DOI:

$10.1063 / 1.3266518$

33 Ludwig, J.; An, L.; Pattengale, B.; Kong, Q. Y.; Zhang, X. Y.; Xi, P. X.; Huang, J. Ultrafast Hole Trapping and Relaxation Dynamics in P-Type CuS Nanodisks J. Phys. Chem. Lett. 2015, 6, 2671- 2675DOI:

10.1021/acs.jpclett.5b01078

34 Pattrick, R. A. D.; Mosselmans, J. F. W.; Charnock, J. M.; England, K. E. R.; Helz, G. R.; Garner, C. D.; Vaughan, D. J. The Structure of Amorphous Copper Sulfide Precipitates: An X-Ray Absorption Study Geochim. Cosmochim. Acta 1997, 61, 2023- 2036DOI: 10.1016/S0016-7037(97)00061-6

$35 \mathrm{Kau}$, L. S.; Spirasolomon, D. J.; Pennerhahn, J. E.; Hodgson, K. O.; Solomon, E. I. X-Ray Absorption-Edge Determination of the Oxidation-State and Coordination-Number of Copper - Application to the Type-3 Site in Rhus-Vernicifera Laccase and Its Reaction with Oxygen J. Am. Chem. Soc. 1987, 109, 6433-6442DOI: 10.1021/ja00255a032

36 Pattengale, B.; Ludwig, J.; Huang, J. Atomic Insight into the W-Doping Effect on Carrier Dynamics and Photoelectrochemical Properties of $\mathrm{BiVO}_{4}$ Photoanodes J. Phys. Chem. C 2016, 120, 1421- 1427DOI: 10.1021/acs.jpcc.5b11451

37 Rao, M. J.; Shibata, T.; Chattopadhyay, S.; Nag, A. Origin of Photoluminescence and XAFS Study of (ZnS) ${ }_{1}$ $x\left(\right.$ AgInS $\left._{2}\right) x$ Nanocrystals J. Phys. Chem. Lett. 2014, 5, 167-173DOI: 10.1021/jz402443y

38 Nag, A.; Chung, D. S.; Dolzhnikov, D. S.; Dimitrijevic, N. M.; Chattopadhyay, S.; Shibata, T.; Talapin, D. V. Effect of Metal Ions on Photoluminescence, Charge Transport, Magnetic and Catalytic Properties of AllInorganic Colloidal Nanocrystals and Nanocrystal Solids J. Am. Chem. Soc. 2012, 134, 13604-13615DOI: 10.1021/ja301285x

39 Zhou, Y. L.; Hu, W. H.; Ludwig, J.; Huang, J. Exceptionally Robust CulnS 2 /ZnS Nanoparticles as Single Component Photocatalysts for $\mathrm{H}_{2}$ Evolution J. Phys. Chem. C 2017, 121, 19031-19035DOI: 10.1021/acs.jpcc.7b05241

40 Aiga, N.; Jia, Q. X.; Watanabe, K.; Kudo, A.; Sugimoto, T.; Matsumoto, Y. Electron-Phonon Coupling Dynamics at Oxygen Evolution Sites of Visible-Light-Driven Photocatalyst: Bismuth Vanadate J. Phys. Chem. C 2013, 117, 9881-9886DOI: 10.1021/jp4013027

41 Huang, Z. Q.In Situ Probe of Photocarrier Dynamics in Water-Splitting Hematite (Alpha- $\mathrm{Fe}_{2} \mathrm{O}_{3}$ ) Electrodes Energy Enviro . Sci. 2012, 5, 8923-8926DOI: 10.1039/c2ee22681b

42 Hassan, A.Charge Carriers Modulate the Bonding of Semiconductor Nanoparticle Dopants as Revealed by Time-Resolved X-Ray Spectroscopy ACS Nano 2017, 11, 10070-10076DOI: 10.1021/acsnano.7b04414 